Original Research Article

\title{
Comparison of pattern of self-medication among urban and rural population of Telangana state, India
}

\author{
Mary Rohini Pentareddy*, Prasanna Vedula, Roopa B., Jagadish Chandra L., \\ S. Amarendar
}

Department of Pharmacology, RVM Institute of Medical Sciences and Research centre, Siddipet, Telangana, India

Received: 15 September 2017 Accepted: 03 October 2017

\section{*Correspondence to:}

Dr. Mary Rohini Pentareddy, Email: drmaryrohini@ yahoo.co.in

Copyright: (C) the author(s), publisher and licensee Medip Academy. This is an openaccess article distributed under the terms of the Creative Commons Attribution NonCommercial License, which permits unrestricted noncommercial use, distribution, and reproduction in any medium, provided the original work is properly cited.

\begin{abstract}
Background: Self-medication is one of the components of self-care, which may treat the disease or result in worsening of the condition due to irrational use of drug. ${ }^{1}$ In developing countries like India, self-medication is a common practice as it provides a low-cost alternative for people who cannot afford the high cost of clinical service, and is time efficient.

Methods: A total of 110 participants completed the study. A printed questionnaire was given to those who were willing to participate in the study and came to buy medicines without consulting a doctor to various pharmacy outlets. Results: Among the group of drugs used antibiotics were the common drugs used in rural area $(74 \%)$ and cough suppressants $(50 \%)$ in urban area. Symptoms for opting self-medication were fever and common cold in both the groups. Individuals in both areas took self-medication based on their previous prescriptions (rural $42 \%$ vs urban $41.6 \%$ ) and advertisements. Rural individuals preferred self-medication with the opinion of saving time and urban people felt that it was less expensive.

Conclusions: There is a difference in the pattern self-medication among rural and urban individuals. It is also to be noted that use of antibiotics may result in problems related to drug resistance. So, it would be advisable to restrict the sale of antibiotics as over the counter drugs.
\end{abstract}

Keywords: Antibiotics, Over the counter drugs, Rural population, Urban population

\section{INTRODUCTION}

Self-medication is defined as the use of medication by a patient on his own initiative or on the advice of a pharmacist or a lay person instead of consulting a medical practitioner. (WHO, 2000).

Medicines for self-medication are often called nonprescription or over the counter (OTC) drugs and are available without a doctor's prescription through pharmacies. Medicines that require a doctor's prescription are called prescription products. ${ }^{2}$
Self-medication is one of the components of self-care, which may treat the disease or result in worsening of the condition due to irrational use of drug. According to WHO responsible self-medication is the practice where by individuals treat their illness and conditions with medicine which are approved and available without prescription and which are safe and effective when used as directed ${ }^{1}$. However, it is also recognized that responsible selfmedication must be accompanied by appropriate health information. ${ }^{3}$ According to some studies, it was found that the burden of self-medication with antibiotics is higher in developing countries than in developed countries. ${ }^{4}$ The 
increased advertising of pharmaceuticals increases concerns of incorrect self-diagnosis, drug interaction, and use of drugs other than for the original indication ${ }^{5}$. Because of self-medication, morbidity is increasing on regular basis. ${ }^{6-8}$

Even though self-medication is useful to treat mild to treat mild to moderate illness, improper self-medication with antibiotics and other drugs may lead to antibiotic resistance, adverse drug reactions and drug interactions. The aim of our study was to compare pattern of selfmedication among urban and rural areas, and find out how they choose the drug for their disease and to asses' awareness of adverse effects with drugs.

\section{METHODS}

Study was started after obtaining permission from Institutional Ethics Committee. This is a cross- sectional, questionnaire based study. The study was conducted at Hyderabad for urban population and villages of Medak district for rural population of Telangana state during the period of April 2017 to June 2017.

\section{Inclusion criteria}

- Persons purchasing medicines at pharmacy outlets without prescription

- Persons purchasing medicines at pharmacy outlets with previous prescriptions at pharmacy outlets

- Persons willing to participate and give informed consent.

\section{Exclusion criteria}

- All individuals visiting pharmacy outlets with prescription after consulting a doctor for present problem

- Persons not willing to participate and give informed consent.

\section{Data collection tool: the questionnaire}

A structured questionnaire was prepared after literature review, which contained 15 questions relating to the reasons for self-medication, group of drugs used, disease for which it was opted, awareness of adverse effects with drugs. After obtaining informed consent, printed questionnaire was given to those who met inclusion criteria and came to various pharmacy outlets at Hyderabad and Medak districts of Telangana. A total of 110 participants completed the study.

\section{Statistical analysis}

Data were entered in MS excel 2007, same were exported into STATA (version 10). Categorical data were analysed for associations using chi square test.

$P$ value $<0.05$ was considered statistically significant.

\section{RESULTS}

A total of 110 individuals participated in the study. Out of them 60 people were from the urban area and 50 people were from rural area. It was observed that, $24 \%$ participants in rural area and $48 \%$ participants in urban area not only took self-medication but also encouraged others to do so. Antibiotics (74\%) were the most commonly used class of drugs, followed by cough suppressants (20\%) and multivitamins (6\%) among the rural population, as shown in Figure 1. Unlike rural area, Urban people self-medicated with cough suppressants $(50 \%)$ more commonly, followed by antibiotics (16\%), multivitamins (13.3\%) and analgesics (11.6\%), shown in Figure 2. There is a statistically significant difference between rural and urban individuals in terms of usage of antibiotics $(\mathrm{P}$ value $<0.01)$ and cough suppressants $(\mathrm{P}$ value $<0.01)$.

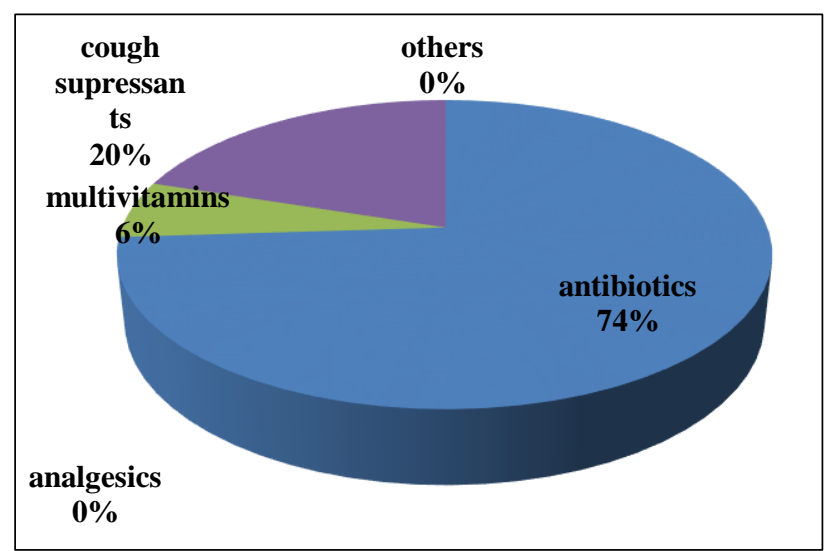

Figure 1: Group of drugs used in rural area.

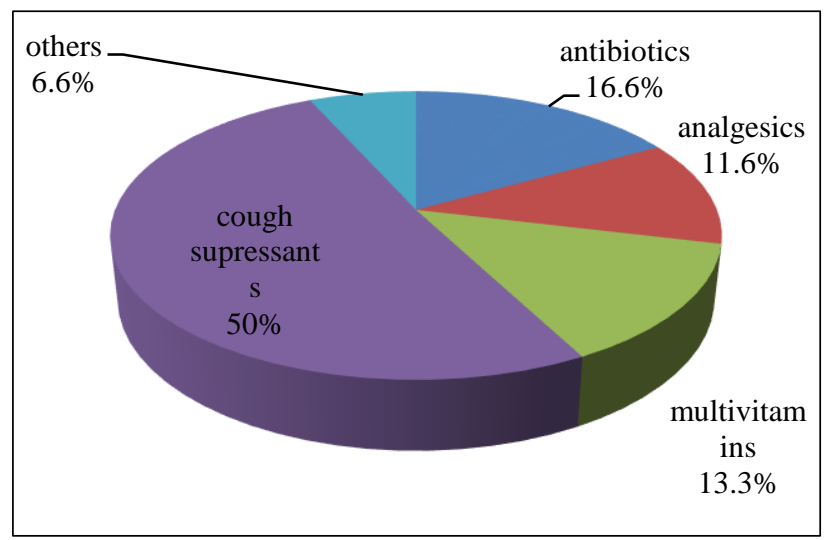

Figure 2: Group of drugs used in urban area.

In this study rural population preferred to take selfmedication for symptoms like fever $(54 \%)$ common cold $(23 \%)$ cough $(18 \%)$ headache $(3 \%)$ and diarrhoea $(2 \%)$ whereas in Urban population the reason for seeking selfmedication was for fever $(40 \%)$ cough $(25 \%)$ common cold and headache $(16.60 \%)$ and diarrhoea $(6.6 \%)$, as shown in Figure 3. Previous prescriptions were the most important source of drug information for self-medication among both rural and urban population, $42 \%$ and $41.6 \%$ respectively 
followed by advertisements (rural 28\%, urban $23.3 \%$ ) and literature on browsing the internet (rural4\%, and urban $21.6 \%$ ), shown in Figure 4.

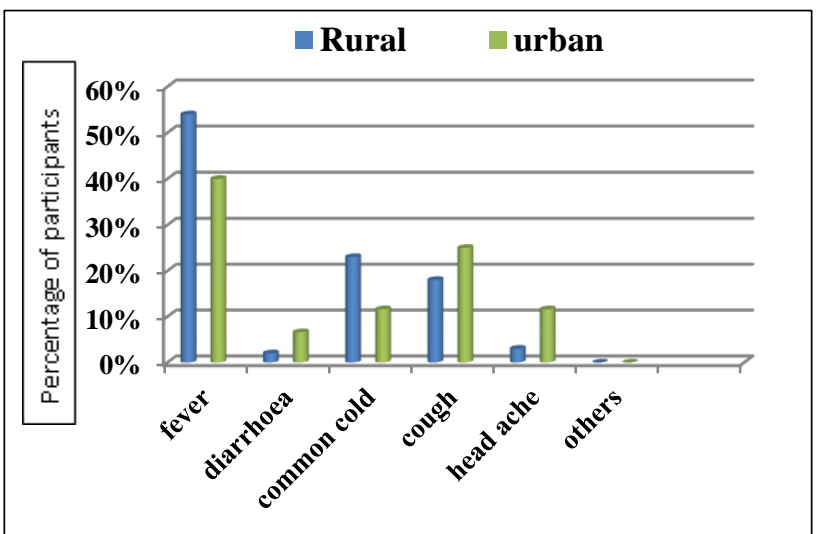

Figure 3: Diseases for which self-medication was taken.

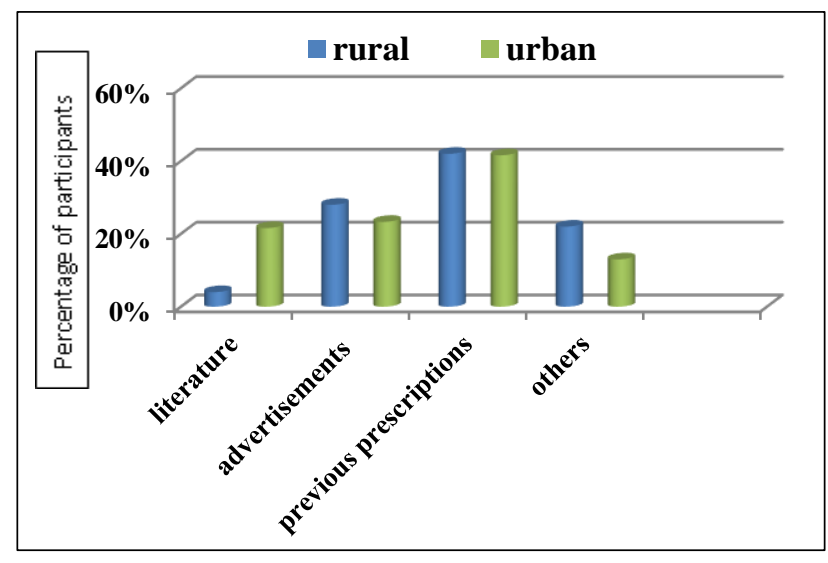

Figure 4: Source of drug information.

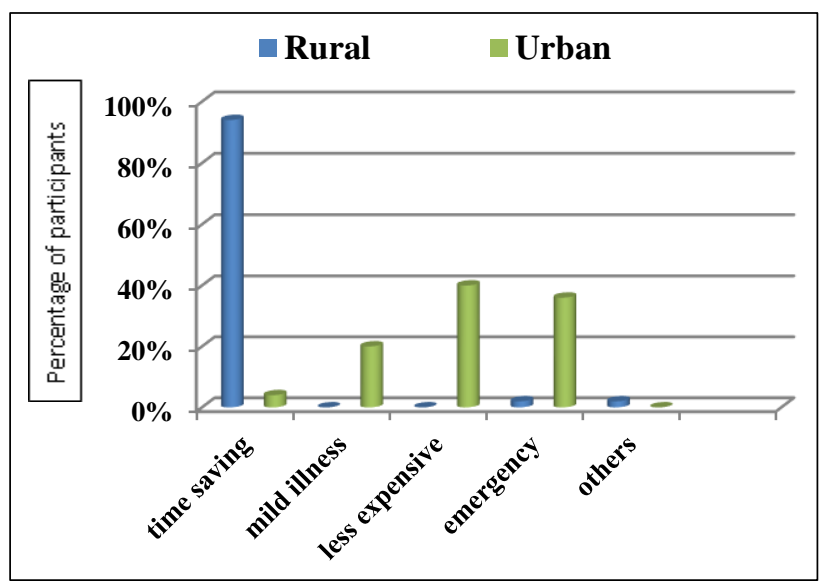

Figure 5: Reasons for seeking self-medication.

The reason for preferring self-medication instead of consulting a doctor was time saving in rural populations (94\%), emergency (2\%) and others (2\%), whereas reasons for seeking self-medication among urban population, was less expensive (40\%), emergency (36\%) and $20 \%$ of them felt that their illness was mild, which is shown in Figure 5.

Awareness regarding completing the course of medication was less among rural population (30\%) compared to urban population (46.6\%). Majority of consumers in rural area who self-medicated antibiotics bought the medicines randomly $(54 \%)$ instead of taking full course, while only $(25 \%)$ of urban consumers bought the medicines randomly. Duration they usually self-medicate was 3 days (38\% rural $46.6 \%$ urban), 5 days (30\% rural and $28.3 \%$ urban), till symptoms subside (14\% rural and $15 \%$ urban), and 7 days (14\% rural, and $10 \%$ urban). $41.6 \%$ in urban population and $20 \%$ in rural population experienced side effects, among which allergy was the most common side effect (urban $30 \%$ and rural $66 \%$ ) followed by headache (urban $25 \%$, rural $6 \%$ ), vomiting (urban $1.6 \%$ and rural $24 \%$ ) and acidity (urban $16.6 \%$ and rural $0 \%$ ).

People aware of drug interactions were $48.3 \%$ in urban area and $66 \%$ in rural area while procuring non-prescription drug, $45 \%$ of urban population and $96 \%$ of rural population always check expiry date of the medicine, $36.6 \%$ of urban population check expiry date sometimes and $11.6 \%$ of urban population never check expiry date while buying medicines. $90 \%$ of rural population and $33.3 \%$ of urban population opined that non-prescription drugs can never be used safely in pregnant woman, children and elderly patients, whereas $40 \%$ of urban population say that they can be used safely. Generic drugs are the most commonly self-medicated drug among rural population (90\%) whereas among urban population $(26 \%)$ of them buy cheaper brand drugs, $25 \%$ of them buy generic drugs, $10 \%$ of them prefer foreign company drug and 39\% didn't have any preference.

\section{DISCUSSION}

Many of the individuals often practice self-medication for various medical illnesses. This study was conducted among the individuals coming to the pharmacy for drugs without any prescription. We preferred this group, as they would give a correct picture regarding the pattern of selfmedication in rural and urban areas. Our results indicate that most commonly used drug among the rural population was antibiotics (74\%) and urban population used more of cough suppressants $(50 \%)$ followed by antibiotics $(16.6 \%)$.

In the study conducted by Banerjee I et al, antibiotics were the frequently used drugs for self-medication similar to our study, whereas our findings were different from that of Priyadarshini et al, Aqeel et al who found that analgesics were the most commonly used class of drugs. ${ }^{9-11}$ Reasons for seeking self-medication were fever, cough, pain and common cold, similar to that of Aqeel et al who found fever was the most common reason for self-medication. We observed in our study that rural individuals preferred self-medication due to lack of time $(94 \%)$ while urban individuals felt that doctor consultation was expensive 
(40\%) and preferred self-medication in emergency situation $(36 \%)$. Lack of medical facilities in rural areas requiring them to travel nearest town may be the reason for seeking self-medication. Our study revealed that rural population were more aware of the expiry date of drugs $(96 \%)$ than urban population $(36.6 \%)$. Urban population preferred cheaper brand drugs $(26.6 \%)$ and generic drugs $(25 \%)$. Side effects experienced were, drug allergy as the common side effect (rural 66\%, urban individuals 30\%), followed by headache, vomiting and acidity.

The awareness of drug interactions among both groups (rural 66\% urban 48.3\%) was fairly high. Rural population (90\%) felt that self-medication was not safe in pregnancy, elderly and children while only $33.3 \%$ of the urban individuals had similar opinion. Most of the individuals took the self-medication for 3-5 days. Antibiotics being the most commonly used drug in rural areas could result in antibiotic resistance due to insufficient dose (or) duration of usage. Antimicrobial resistance(AMR) threatens the effective prevention and treatment of an ever-increasing range of infections caused by bacteria, parasites, viruses and fungi. ${ }^{12}$

Limitations of the study was larger sample size could have given clearer picture regarding the difference in pattern of self-medication.

\section{CONCLUSION}

There is a difference in the pattern self-medication among rural and urban individuals. Rural individuals used antibiotics mainly while urban population used cough suppressants. Rural population felt self-medication is time saving while urban population felt it was less expensive. It is to be noted that use of antibiotics may result in problems related to drug resistance. So, it would be advisable to restrict the sale of antibiotics as over the counter drugs. An increase in awareness of this among pharmacists may be helpful. Encouragement for doctors to practice in rural areas may reduce the use of self-medication among rural population. Awareness of using self-medication among pregnant and in elderly is to be increased. Rural individuals are preferring generic drugs which are cheaper.

\section{ACKNOWLEDGEMENTS}

Authors would like to thank Mr. Naresh, clerk in the Department of Pharmacology for helping us in collecting data from rural areas of medak district.

Funding: No funding sources Conflict of interest: None declared

Ethical approval: The study was approved by the Institutional Ethics Committee

\section{REFERENCES}

1. World Health Organization: The role of the pharmacist in self-medication. Available at: http://www.apps.who.int/medicinedocs/pdf/whozip32e/ whozip32e.pdf [last accessed on 2010 Apr 23].

2. Responsible self-care and self-medication; A Worldwide Review of consumer survey. Available at: http://www.wsmi.org/wpcontent/data/pdf/wsmibro3.pdf.

3. World health organization (WHO): Guidelines for the regulatory assessment of Medicinal products for use in self-medication. Available at: http://www.apps.who.int/medicinedocs/en/d/Js2218e/.

4. Napolitano F, Izzo MT, Di Giuseppe G, Angelillo IF. Public knowledge, attitudes, and experience regarding the use of antibiotics in Italy. PLoS One. 2013;8(12):e84177. [PMC free article] [PubMed] [Cross Ref]

5. Burak LJ, Damico A. College students' use of widely advertised medications. J Am Coll Health. 2000;49(3):118-21. [PubMed] [Cross Ref].

6. Aswapokee N, Vaithayapichet S, Heller RF. Pattern of antibiotic use in medical wards of a university hospital, Bangkok, Thailand. Rev Infect Dis. 1990;12(1):136-41. [PubMed] [Cross Ref].

7. Osemene KP, Lamikanra A. A study of the prevalence of self-medication practice among university students in southwestern Nigeria. Trop J Pharm Res. 2012;11(4):683-9.

8. World Health Organization. Global strategy for containment of antimicrobial resistance. Communicable diseases surveillance and response (CRS). WHO/CDS/CSR/DRS/2001.2. 2001. Available at: http://www.who.int/csr/resources/publications/drugresist /en/EGlobal_Strat.pdf.

9. Banerjee I, Bhadury T. Self-medication practice among undergraduate medical students in a tertiary care medical college, West Bengal. J Postgraduate Medicine. 2012;58(2):127.

10. Bai PG, Kumar RP. Impact of Self-medication among Urban and Rural Literate Population. Journal of International Medicine and Dentistry. 2016;3(2):73-9.

11. Aqeel T, Shabbir A, Basharat H, Bukhari M, Mobin S, Shahid H, et al. Prevalence of Self-medication among Urban and Rural Population of lslamabad, Pakistan. Trop J Pharm Res. 2014;13(4):627.

12. World Health Organization: United Nations high-level meeting on antimicrobial resistance, 21 September 2016, New York, USA. Available at: http://www.who.int/antimicrobialresistance/events/UNGA-meeting-amr-sept2016/en/

Cite this article as: Pentareddy MR, Vedula $\mathrm{P}$, Roopa B, Chandra LJ, Amarendar S. Comparison of pattern of self-medication among urban and rural population of Telangana state. Int J Basic Clin Pharmacol 2017;6:2723-6. 